\title{
Rapidly progressive subacute motor neuronopathy disclosing type B2 thymoma
}

Neuronopatia motora subaguda rapidamente progressiva associada com timoma tipo B2

Paulo Victor Sgobbi de Souza1, Thiago Bortholin', Wladimir Bocca Vieira de Rezende Pinto', Acary Souza

Bulle Oliveira ${ }^{1}$

A 73-year-old man presented with a three-month history of muscle wasting, cramps and marked weight loss. Examination revealed severe global amyotrophy (Figure), fasciculations, reduced deep tendon reflexes and flaccid quadriparesis. Nerve conduction studies were unremarkable. Needle electromyography showed acute and chronic partial denervation in the cervical, thoracic and lumbosacral segments. A full-body CT scan disclosed a large mass in the anterior mediastinum, which showed a type B2 thymoma.

Paraneoplastic neuropathies represent an expanding group of immune-mediated neuropathies associated with a known or unidentified neoplasm ${ }^{1}$. Pure motor neuropathy is represented by subacute motor neuronopathy ${ }^{1}$, commonly associated with Hodgkin's and non-Hodgkin's lymphoma ${ }^{1,2}$ and, rarely, with thymoma ${ }^{2}$.
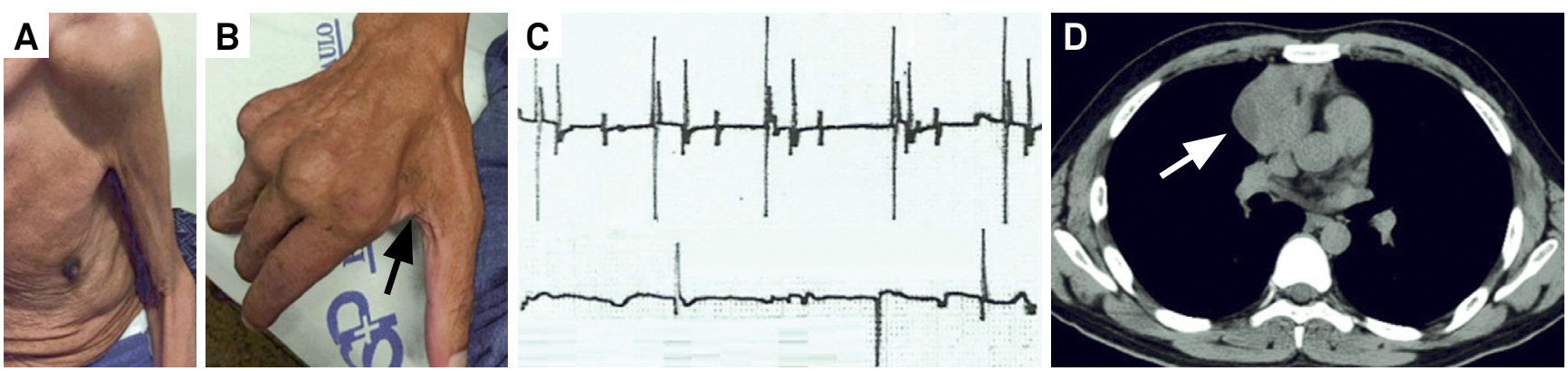

Figure. Findings in subacute motor neuronopathy. Severe muscle wasting in proximal (A) and distal muscle groups (B; black arrow). (C) Rarefaction of interference patterns in submaximal voluntary contraction, and fibrillation and positive sharp wave at rest.

(D) Chest CT scan showed a large mass in the anterior mediastinum (white arrow).

\section{References}

1. Graus F, Dalmau J. Paraneoplastic neuropathies. Curr Opin Neurol. 2013;26(5):489-95. https://doi.org/10.1097/WC0.0b013e328364c020
2. Stoll DB, Lublin F, Brodovsky H, Laucius JF, Patchefsky A, Cooper H. Association of subacute motor neuronopathy with thymoma. Cancer. 1984;54(4):770-2. https://doi.org/10.1002/10970142(1984)54:4<770::AID-CNCR2820540430>3.0.CO;2-E

1 Universidade Federal de São Paulo, Departamento de Neurologia e Neurocirurgia, Divisão de Doenças Neuromusculares, São Paulo SP, Brasil. Correspondence: Paulo Victor Sgobbi de Souza; Departamento de Neurologia e Neurocirurgia da UNIFESP; Rua Estado de Israel Street, 899 ; $04022-002$ São Paulo SP, Brasil; E-mail: pvsgobbi@gmail.com

Conflict of interest: There is no conflict of interest to declare.

Received 22 February 2017; Accepted 11 September 2017. 